\title{
Mechanical properties of prestressed joists made using recycled ceramic aggregates
}

Fernando López Gayarre ${ }^{(1)}$; Jesús Suárez González ${ }^{(1)}$; Miguel A. Serrano López ${ }^{(1)}$ Carlos LópezColina Pérez ${ }^{(1)}$; Pedro J. Fernández Arias ${ }^{(1)}$

${ }^{(1)}$ Polytechnic School of Engineering - University of Oviedo. Campus de Viesques, 33203 Gijón, Spain.

\section{Abstract}

This work addresses the reuse of recycled bricks aggregates (RBA), coming from faulty bricks for manufacturing prestressed concrete joists, with different percentages of these recycled aggregates, in building floor slabs.
\end{abstract}

The prestressed joists were manufactured in a local factory with precast facilities and later they were tested to determine their flexural and shear strength. In addition, the set joist-rib-compression layer was also tested in order to assess its flexural and shear strength of the whole set.

The results obtained are favourable using RBA percentages up to $35 \%$, but if the set joist-ribcompression layer is considered, using conventional concrete on the rib and the compression layer, this percentage could reach $70 \%$.

\section{Keywords}

Recycled brick aggregates, prestressed joists, floor slabs, flexural behaviour, shear behaviour.

\section{Introduction}

The use of recycled aggregates from construction and demolition waste (C\&DW) is becoming an increasingly common practice due to the increase in the costs of extraction of natural resources and the associated environmental damage. The European Union establishes that by 2020 C\&DW should be managed as resources that must be reintroduced into the production system as raw material [1]. Therefore, its recycling will be a priority.

According to research carried out in Spain [2], the most common components of C\&DW are concrete $(12 \%)$ and ceramic materials (54\%) which, once they are separated and crushed properly, generate two different materials: recycled concrete aggregates (RCA) and recycled brick aggregates (RBA).

The initial studies carried out to reuse C\&DW focused on the preparation of concretes used in building and precasting products with low mechanical requirements such as paving blocks, pavement slabs, building blocks, kerbs and hollow bricks for flooring. The results show that, if the water-cement ratio is properly controlled, paying special attention to the effective amount of water used, C\&DW can be used while complying with the regulations established in the corresponding standards. Nowadays, even ultra-high performance concrete has been manufactured incorporating C\&DW.

This study addresses the manufacture of structural precast elements, specifically, prestressed concrete joists used in building floor slabs, using different percentages of RBA coming from faulty bricks. These wastes have an advantage: they do not need to be classified and, on the other hand, they are abundantly available since they constitute between $3 \%$ and $7 \%$ of the production of the ceramic factories [3].

To date, the studies carried out on the reuse of C\&DW in the manufacturing of structural elements, principally reinforced concrete beams (RC beams), considered mainly the use of concrete waste. 
Generally, only the coarse fraction of natural aggregate was replaced. The substitution of the fine fraction is not recommended due to the undesirable effects of the remaining mortar [4]. These studies focus mainly on evaluating the behaviour of structural elements under flexural and shear strength. The most significant results obtained in previous studies are presented below.

With regard to the substitution of the fine and coarse fraction of natural aggregates by recycled concrete aggregates in the manufacture of beams, the work of Sato et al. [4] and of Ajdukiewicz and Kliszczewicz [5] are worthy of mention. They conclude that the ultimate load in bending is nearly the same as that obtained with the control concrete. However, there is a significant increase in deflections, for percentages between $18 \%$ and $40 \%$, when only the coarse fraction is replaced. This rises up to $100 \%$ when the fine fraction of RCA is also included. As a result, the substitution of fine aggregates is clearly discouraged. Similar results were obtained by Choi et al. [5], by analyzing flexural strength performance of beams using fine and/or coarse RCA. They observed a reduction in flexural strength, larger deflections and wider cracks, when compared to concretes with natural aggregates.

When only the coarse fraction is replaced by RCA, the results improved. With a substitution of $100 \%$, Arezoumandi et al. [6] obtained similar results to those of the control concrete in terms of ultimate flexural strength and they also reported a cracking reduction of $7 \%$. Similar results are reported in the works of Bai and Sun [7], Ignjatovic et al. [8], Deng and Yu [9] and Zhao and Sun [10]. Other authors, such as Knaack et al. [11, 12], also observed a noticeable reduction in the initial stiffness.

Tosic et al. [13] carried out a rigorous study of the works published between 2001 and 2015 in which the natural aggregates are replaced by RCA in percentages of $0 \%, 50 \%$ and $100 \%$. This work compares the results obtained in the tests with the predictions using the Eurocode 2 [14]. It concludes that for flexural strength, the average value of the ratio between the results obtained in the tests and those predicted by EC2 (test-to-predicted ratio) is between 1.064 and 1.091. Statistically, the differences are very small.

The beams manufactured with RCA present an ultimate flexural strength similar to those manufactured with conventional concrete for percentages up to $70 \%$, although there is a slight decrease in strength for a substitution of $100 \%$. It is also clear that beam deflections increase when using RCA concrete mainly because the elastic modulus is lower than that of concrete with natural aggregates. A decrease in the cracking moment is also observed. For this reason some authors[15] recommend increasing the cross section depth in order to fulfill the deflection limits imposed by Eurocode 2 [14].

Several studies have also been carried out regarding the shear behaviour of beams with RCA. In most of them only the coarse fraction of natural aggregates was replaced by RCA. Arezoumandi et al. [16] tested beams replacing $100 \%$ of the coarse fraction with RCA while keeping the ratios of water and cement constant. They stated that the shear strength decreases by $12 \%$ when using RCA. Nevertheless, they did not observe variations in load deflection response. In another work by the same authors [18], the results obtained for $50 \%$ of RCA were similar to those obtained for the control concrete. In a similar work, Katkhuda and Shatarat [17] observed a reduction of $15 \%$ in shear strength for a substitution of $50 \%$ of the coarse fraction with RCA and a reduction of $20.6 \%$ for a replacement of $100 \%$, with similar load deflection response in all the cases. Rahal and Alrefaei [18] tested percentages of substitution up to $100 \%$ of the coarse fraction for RCA, with water/cement ratios between 0.5 and 0.54 . In these tests they obtained an $18 \%$ reduction in the shear strength for $100 \%$ replacement of the coarse fraction with RCA. However, other authors such as Chen et al. [19], Ikponmwosa and Salau [20] and Choi and Yun [21] stated that beams with RCA present a shear strength similar to those manufactured with conventional concrete.

Some researchers have conducted studies increasing the amount of cement, when replacing natural aggregates with RCA, in order to compensate for the possible reduction in compressive strength (Ignjatovic et al [22]) or to keep the water/cement ratio constant (González-Fonteboa and MartínezAbella [23]). In these cases, the structural behaviour was similar to that of the control beams although 
an increase of $10 \%$ in deflections was observed in [24] and premature development of cracks was confirmed in [25].

In the aforementioned study by Tosic et al. [13], regarding works published between 2001 and 2015 in which the natural aggregates were replaced by RCA in percentages of $50 \%$ and $100 \%$, it is stated that for the shear strength, the average ratio between the tests results and those predicted by EC2 [14] (test-to-predicted ratio) is close to 1.0 (between 1.030 and 1.060), although with lower precision due to the large dispersion of the results.

Specially noteworthy are the studies carried out by Fathifazl et al. [24] [25], which use the EMV (equivalent mortar volume) method [26] to regulate the mixture. This method takes into account that the concrete waste is a material composed of residual mortar and natural aggregates and therefore each of these two components must be considered separately to calculate the proportions of the mixture. As a consequence, there is a maximum limit of RCA to incorporate into the mixture, which depends on the percentage of RCA residual mortar. Following this procedure, they performed tests replacing $63 \%$ and $74 \%$ of the coarse fraction with RCA from different sources and concluded that, generally the beams manufactured with RCA presented a higher shear strength compared to conventional beams. Therefore, the code provisions for structural design are also applicable to this type of beams without any modification. Similar conclusions were obtained in the tests for flexural strength [27].

A decrease between $0 \%$ and $30 \%$ in the shear strength when is replaced $100 \%$ of the coarse fraction by RCA can be observed. The differences in these percentages are explained because of the different procedures followed to prepare the concrete mixtures, specially with regard to the amount of cement used. In some cases, this amount was increased in order to balance the water/cement $(\mathrm{w} / \mathrm{c})$ ratio due to the higher absorption of the RCA, or to correct the lower compressive strength when using this type of aggregate. Furthermore, the deflections were not so high as in the flexural strength tests.

There is few research into the use of RBA in structural applications. Mohammed et al. [28] compare the flexural behaviour of beams manufactured with RBA from different origins. They used ceramic waste from demolitions, with remains of adhered mortar, but also clean crushed bricks. The percentage of substitution was $100 \%$ of the coarse fraction of natural aggregates, with a constant water/cement ratio. They did not register differences between the two types of waste and concluded that the provisions of $\mathrm{ACl} 318-14$ [29] can be used safely to calculate the cracking bending moment and the flexural strength for this type of beams. In a similar study, Cheng et al. [30] carried out flexural strength tests on beams with $35 \%$ of natural aggregates substituted by recycled clay brick aggregate, concluding that both the bearing capacity and the stiffness decrease slightly.

\section{Aims and scope}

The main aim of this work is to further the knowledge of the application of recycled brick aggregates (RBA), optimizing the manufacture of precast prestressed concrete joists. Regarding this issue, it should be noted that to date no studies have been conducted.

At first sight, recycled brick aggregates (RBA) do not present good enough properties to be used in structural applications because of its low strength and its high level of water absorption. However, some studies carried out [31-33] have shown that the use of this kind of aggregates in middle strength concretes ( $<45 \mathrm{MPa}$ ) produces low decrease of strength for percentages of substitution up to $30 \%$, or even show a better performance for low percentages when only the fine fraction is substituted by RBA $[34,35]$.

In order to contrast the results previously exposed and as a first phase of this research, a study focused to evaluate the applicability of concrete with RBA in precast prestressed joists was published [36]. In that work, the properties of concrete with different percentages of substitution of RBA (for both fine and coarse materials), used in prefabricated concrete structural elements, were studied in detail. The main conclusion of that first phase was that a percentage of substitution of RBA up to $35 \%$ could be 
acceptable. This result led to undertake the manufacture of the joists as the second phase of the research.

The joists were manufactured in the facilities of a local precast concrete company interested in the reuse of the waste generated in a different ceramic'-ç brick manufacturing plant.

\section{Experimental study}

\subsection{Properties of aggregates}

The properties of the aggregates used to manufacture the joists are exposed in the paper previously mentioned [36] which constitutes the first phase of the research and they are shown in table 1. Natural aggregates were a mixture of sand $0 / 4 \mathrm{~mm}$, washed sand $0 / 4 \mathrm{~mm}$ and natural gravel $4 / 10 \mathrm{~mm}$. RBA come from rejected ceramic pieces used in ventilation ducts which were processed in a recycling plant in order to crush and classify them. Their granulometric curves can be observed in figure 1.

\begin{tabular}{lccccc}
\hline Property & Standard & $\begin{array}{c}\text { Washed Sand } \\
0 / 4 \mathrm{~mm}\end{array}$ & $\begin{array}{c}\text { Sand } \\
0 / 4 \mathrm{~mm}\end{array}$ & $\begin{array}{c}\text { Natural gravel } \\
4 / 10 \mathrm{~mm}\end{array}$ & RBA \\
\hline Density $\left(\mathrm{kg} / \mathrm{dm}^{3}\right)$ & EN 1097-6 & 2.65 & 2.65 & 2.65 & 2,00 \\
Water absorption (\%) & EN 1097-6 & 0.50 & 0.60 & 1 & 11.21 \\
Sand equivalent & EN 933-8 & 90 & 78 & - & 88 \\
\hline
\end{tabular}

Table 1. Properties of aggregates.

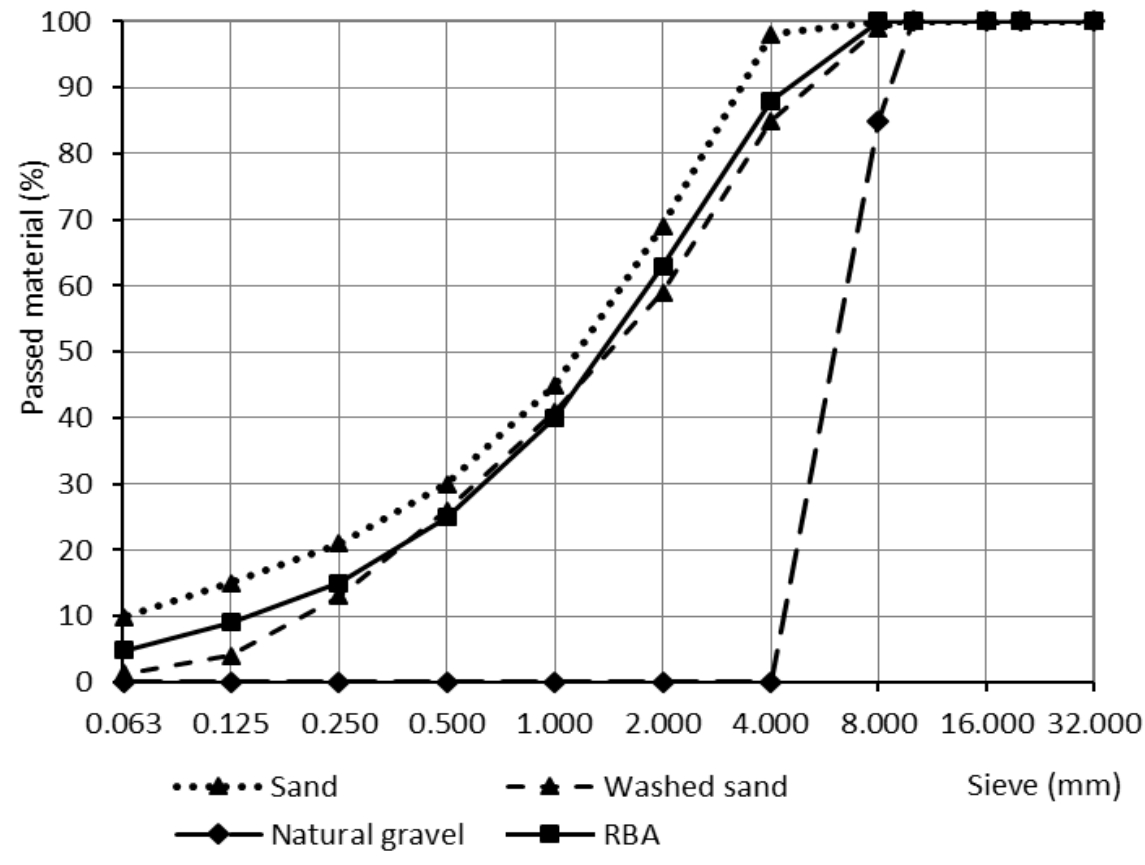

Figure 1. Sieve analysis of aggregates.

\subsection{Proportions of mixtures}

Table 2 shows the proportions used for the manufacture of the joists [36]. In this study the total quantity of water was reduced because in the industrial manufacturing process, due to the strong vibration, an adequate compacting was achieved in all levels of replacement. 


\begin{tabular}{llllll}
\hline \multirow{2}{*}{ Materials } & \multicolumn{5}{l}{ RBA (\%) } \\
& 0 & 20 & 35 & 50 & 70 \\
\hline Cement $\left(\mathrm{kg} / \mathrm{m}^{3}\right)$ & 400 & 400 & 400 & 400 & 400 \\
Natural gravel 4/10 $\left(\mathrm{kg} / \mathrm{m}^{3}\right)$ & 810 & 648 & 421.2 & 210.6 & 63.2 \\
Sand $\left(\mathrm{kg} / \mathrm{m}^{3}\right)$ & 70.0 & 56.0 & 36.4 & 18.2 & 5.5 \\
Washed sand AF-T 0/4 C-L $\left(\mathrm{kg} / \mathrm{m}^{3}\right)$ & 1158.0 & 926.4 & 602.2 & 301.1 & 90.3 \\
RBA $\left(\mathrm{kg} / \mathrm{m}^{3}\right)$ & 0.0 & 307.6 & 538.3 & 769.1 & 1076.7 \\
Water $(\mathrm{I})$ & 142.0 & 151 & 159 & 169 & 180
\end{tabular}

158

159

160

161

162

163

164

165

166

\subsection{Properties of concrete}

The properties of concrete were analyzed in detail in [36]. Table 3 reproduces the results obtained there.

\begin{tabular}{llllll}
\hline & \multicolumn{5}{c}{ RBA $(\%)$} \\
Property & 0 & 20 & 35 & 50 & 70 \\
\hline Occluded air $(\%)$ & 4.6 & 4.8 & 5.1 & 5.7 & 5.7 \\
Density $\left(\mathrm{kg} / \mathrm{m}^{3}\right)$ & 2380 & 2340 & 2250 & 2230 & 2150 \\
Ultrasonic pulse velocity $(\mathrm{UPV})(\mathrm{km} / \mathrm{s})$ & 4.7 & 4.5 & 4.2 & 4.3 & 4.1 \\
Compressive strength $\left(\mathrm{f}_{\mathrm{cm}}\right)(\mathrm{MPa})$ & 59.8 & 55.6 & 52.8 & 54.1 & 46.8 \\
Tensile strength $\left(\mathrm{f}_{\mathrm{ctm}}\right)(\mathrm{MPa})$ & 3.60 & 3.87 & 3.42 & 3.06 & 2.79 \\
Modulus of elasticity $\left(\mathrm{E}_{\mathrm{c}}\right)(\mathrm{GPa})$ & 42.0 & 36.0 & 31 & 28.5 & 22.5 \\
Water absorption $(\%)$ & 5.0 & 5.9 & 8.0 & 10.3 & 11.1 \\
\hline
\end{tabular}

Table 3. Results of the tests of concrete manufactured in the laboratory.

\subsection{Details of the joists}

Self-supporting joists were manufactured with the cross-section shown in figure 2 . The control concrete used for manufacturing the joists was type C45/55 according to EN 206-1 [37]. It had a dry consistency.

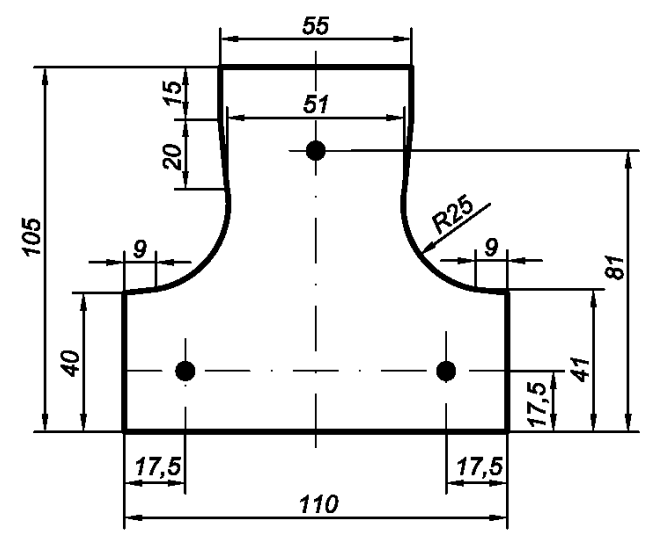

Figure 2. Dimensions of the tested joist and location of the reinforcing wires $(\mathrm{mm})$.

The reinforcement consisted of three $5 \mathrm{~mm}$ diameter steel wires represented as black solid circles in figure 2. The steel type was Y $1770 \mathrm{C}$ [35] according to EN-10027 [38], with an ultimate tensile strength $\left(\mathrm{f}_{\mathrm{pk}}\right)$ of $1770 \mathrm{~N} / \mathrm{mm}^{2}$. The initial applied stress in the pre-stressing process was $1350 \mathrm{MPa}$ for all the joists and the total drop for the infinite time period is estimated at $28.8 \%$.

The theoretical strength values of the joists manufactured with conventional concrete (provided by the precast manufacturing company), are shown in table 4 . In this table, Mo is the decompression bending moment of the lowest fiber in the cross-section, $\mathrm{Mo}^{1}$ is the bending moment that produces zero stress in the fiber of the cross-section located at the deepest point of the lower reinforcement, and $\mathrm{Mo}^{2}$ is the bending moment at which a crack with a width of $0.2 \mathrm{~mm}$ is reached. The right column in table 4 shows the equivalent loads for a four- point flexural test with a span of $3.85 \mathrm{~m}$ (Figure 4) 
according to EN 15037-1 [39] and for a shear strength test with the same span (Figure 5), according to the same code.

\begin{tabular}{ccc}
\hline & $(\mathrm{kNm})$ & Load $(\mathrm{kN})$ \\
\hline Ultimate positive moment $(\mathrm{Mu}+)$ & 3.020 & 4.706 \\
Service moment (Mo) & 1.560 & 2.431 \\
$\mathrm{Mo}^{1}$ & 1.690 & 2.634 \\
$\mathrm{Mo}^{2}$ & 2.270 & 3.538 \\
Ultimate shear load (Vu) & & 13.876 \\
\hline
\end{tabular}

\subsection{Manufacturing of the joists}

The joists were manufactured following the standard procedures used by the company for the elaboration and subsequent curing process, using percentages of substitution of RBA up to $70 \%$, None of the joists were manufactured with $100 \%$ RBA because the compressive strength of concrete with this percentage of substitution was below the minimum value set by the company. Figure 3 shows the manufacturing process and the cross-section of one of the joists.
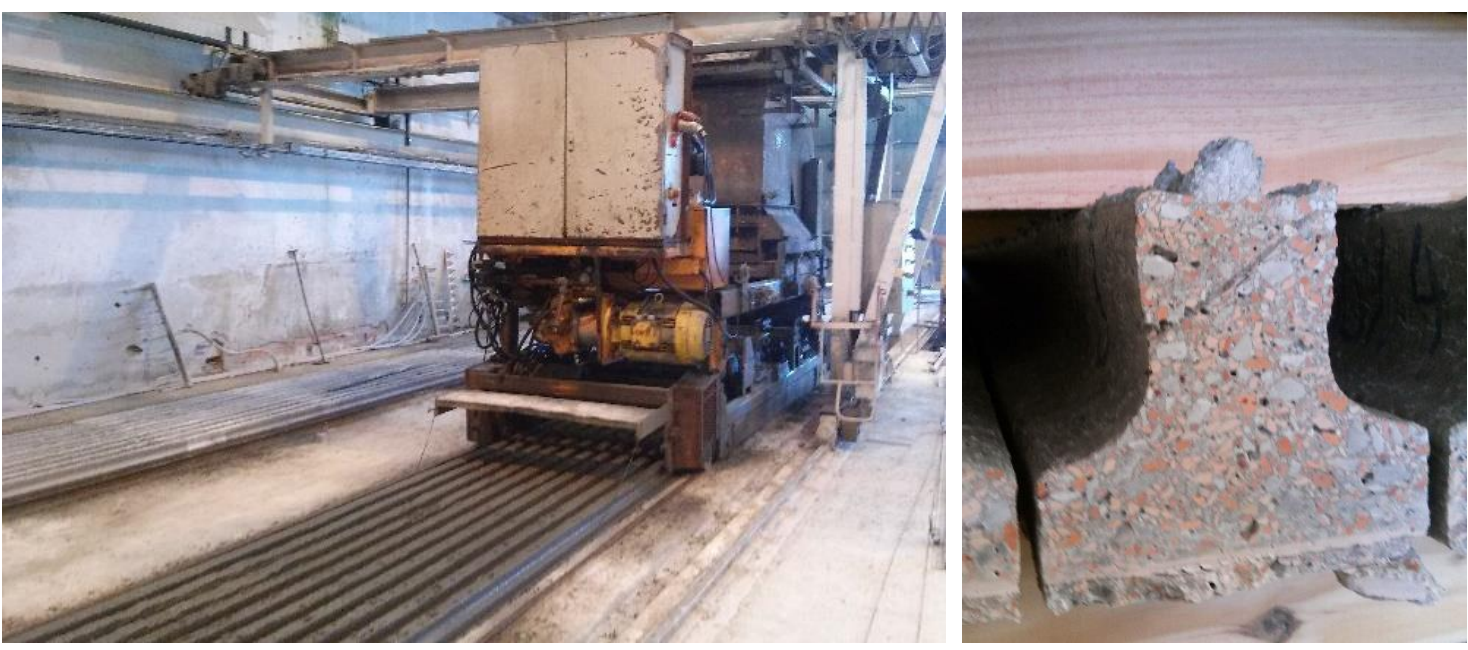

Figure 3. Manufacturing process and cross-section of one of the joists

\subsection{Flexural strength test of the joists}

The flexural strength tests were carried out after 90 days according to EN 15037-1 [39] for simplysupported joists according to the plot shown in figure 4.
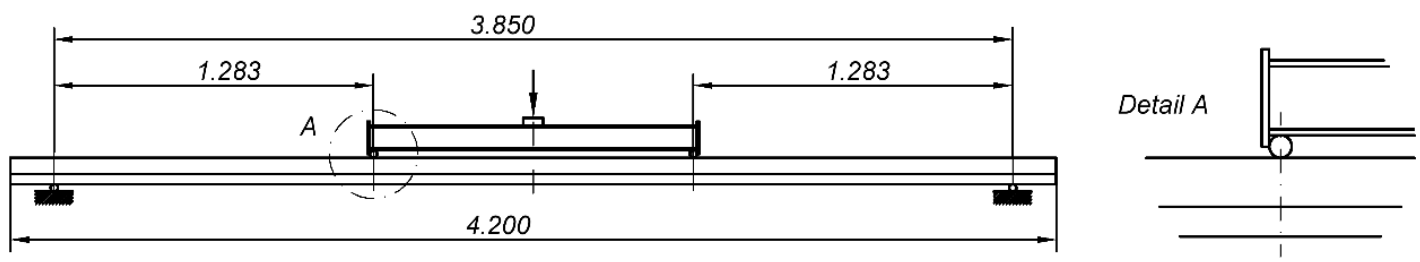

Figure 4. Scheme of the flexural strength test (dimensions in $\mathrm{m}$ ).

Two joists were tested for each RBA percentage of substitution, obtaining the load-displacement curve for each one. In order to simplify the presentation of results, an average curve has been plotted for each pair of curves. In figure 5 the average results are shown. 

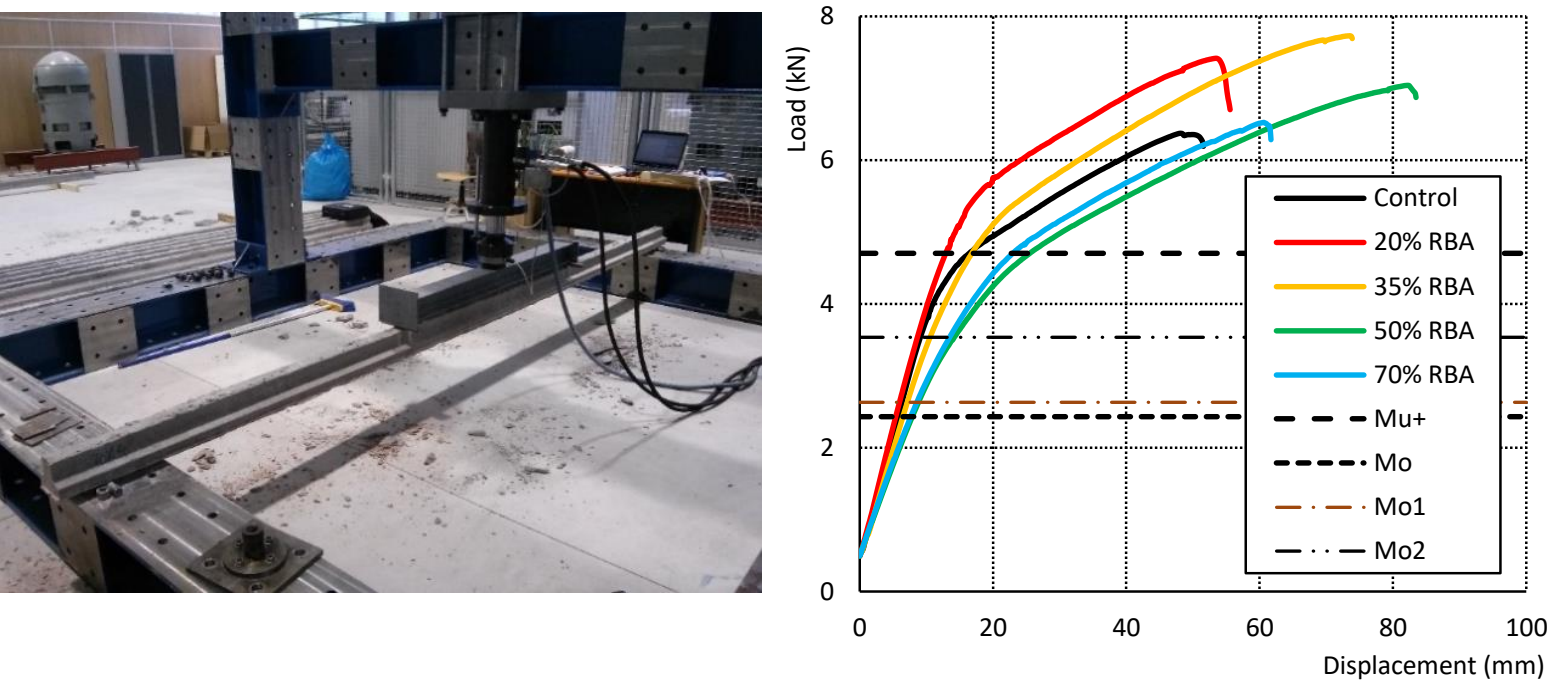

198

Figure 5. A Flexural strength test and the average load-displacement curves.

This figure also shows the loads corresponding to the ultimate positive bending moment $(\mathrm{Mu}+)$ and the serviceability bending moment (Mo). These moments are provided by the precast facility for the joists manufactured with the control concrete. The equivalent loads for bending moments $\mathrm{Mo}^{1}$ and $\mathrm{Mo}^{2}$ have also been plotted. As above commented, the loads corresponding to these bending moments, for a span of $3.85 \mathrm{~m}$ in the four-point flexural strength test, are presented in the right column of table 4 .

\subsection{Shear strength test of the joists}

The shear strength tests were carried out after 92 days according to standard EN 15037-1 [39] for simply supported joists. Figure 6 shows the distances of the supports and the location of the applied load.
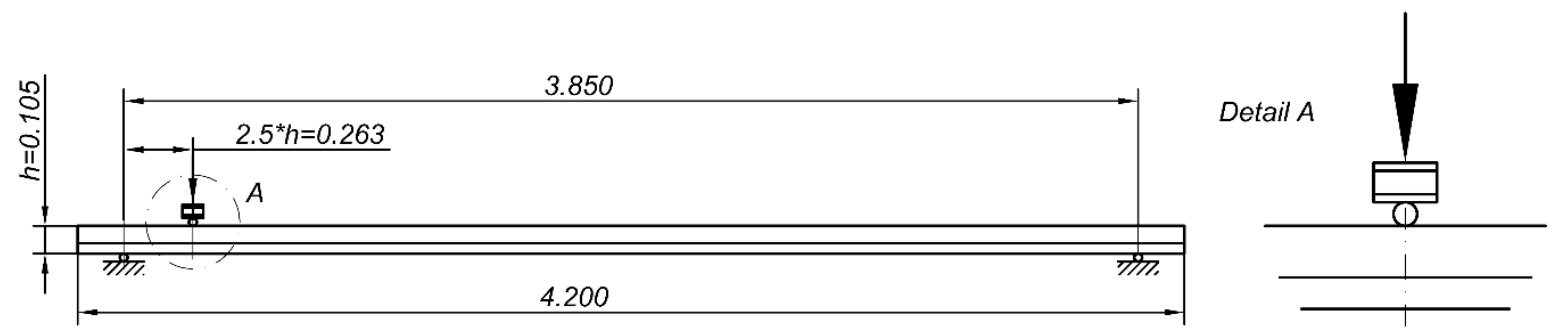

Figure 6. Scheme of the shear strength test (dimensions in $\mathrm{m}$ ).

The same as for the flexural strength tests, the loads and the corresponding displacements were recorded for subsequent analysis. The plots with the average results for each pair of tests are shown in Figure 7. In addition, the load corresponding to the ultimate shear strength for a control concrete joist, $\mathrm{V}_{\mathrm{u}}$, is presented as a reference in table 4 . 


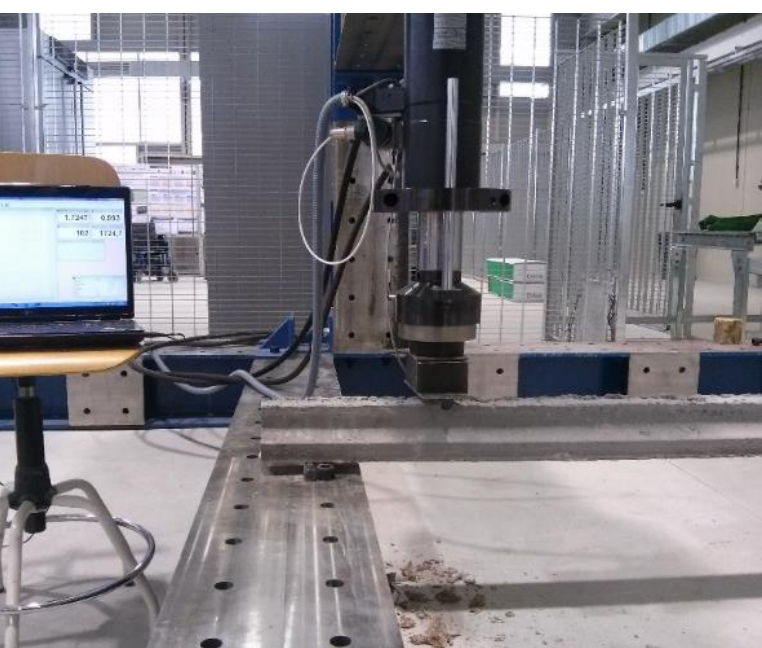

217 used in these cases are non-resistant.

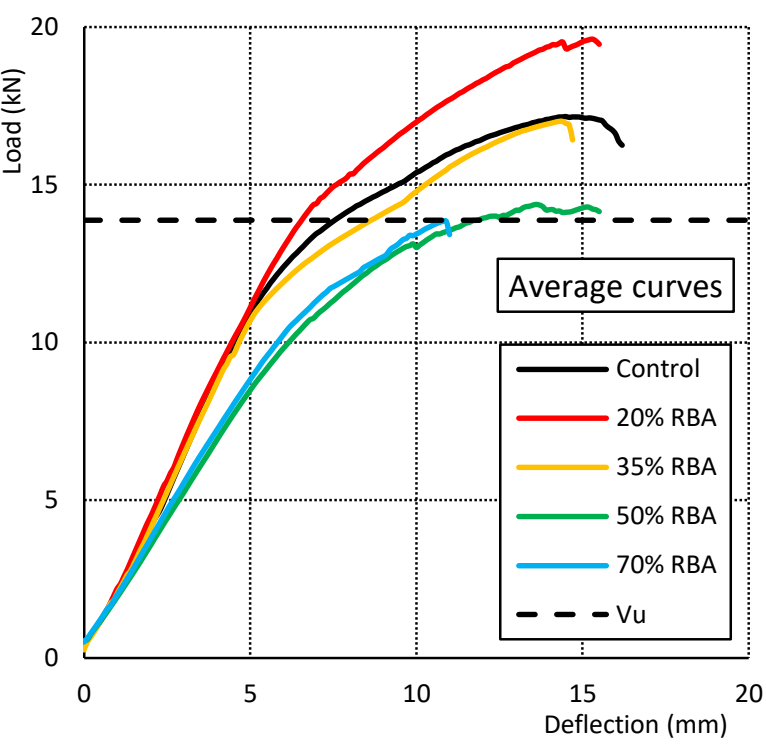

Figure 7. A shear strength test and the average load-displacement curves.

\subsection{Flexural strength test for a joist-rib-layer compression set}

In a real floor slab the joists do not work alone, but as part of a resistant cross-section formed by the joist, the rib and the compression layer (Figure 8). The result is that the joists-ribs-compression layer sets are the resistant elements that support the loads applied to the floor slab, since the floor blocks

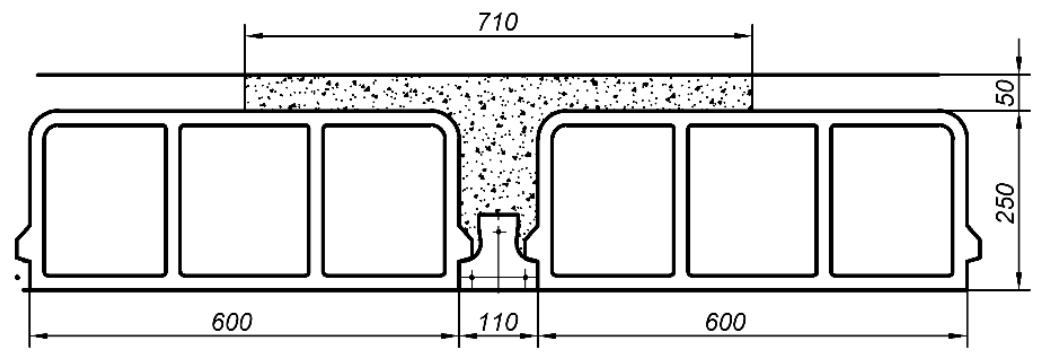

Figure 8. Unidirectional floor slab with joist and floor blocks (dimensions in $\mathrm{mm}$ ).
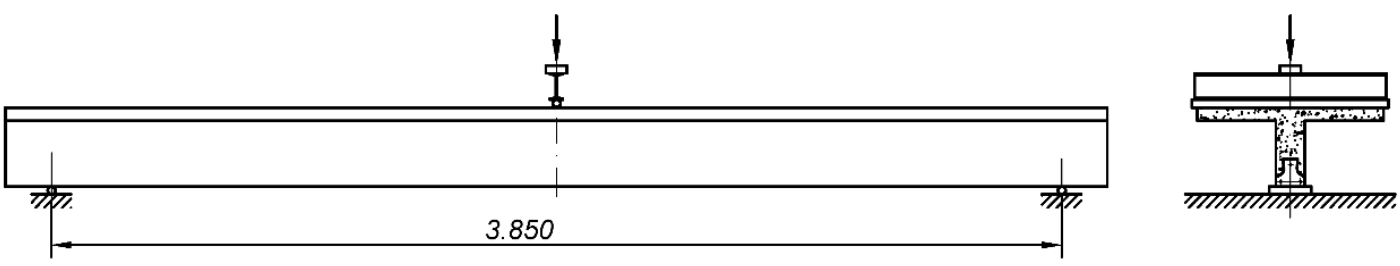

Figure 9. Scheme used in the flexural strength test of the joist-rib-compression layer set (dimensions in $\mathrm{m}$ ).

The concrete used for the compression layer was C25/35 following EN 206-1 [40]. The complete joistrib-compression layer set was tested to determine the flexural strength in a three-point flexural test (as shown in figure 9), after 90 days of curing. The load-displacement curves (figure 10) are similar to those from previous tests, where the average results for different substitution percentages are presented and compared with those obtained in the control concrete. 


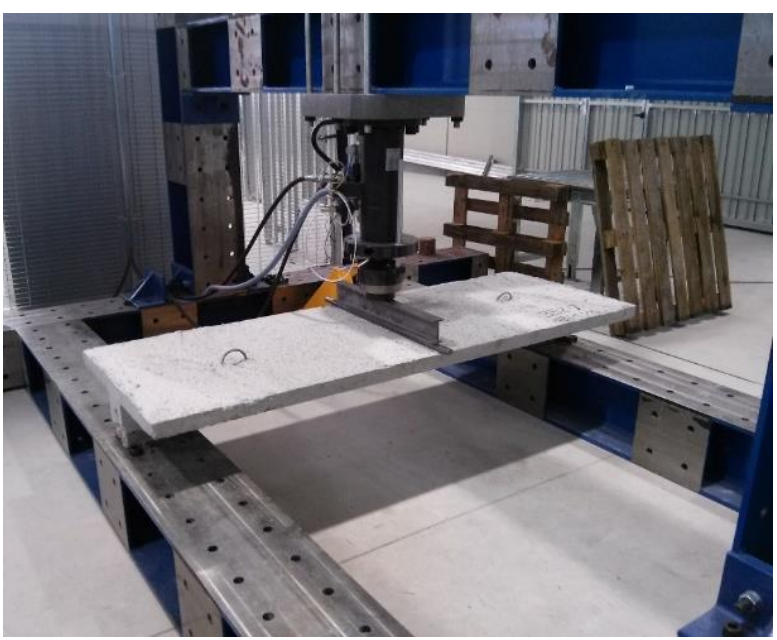

233

\section{Analysis of results}

\subsection{Flexural strength test of the joists} $21 \%$ for a $35 \%$ of substitution level with RBA.

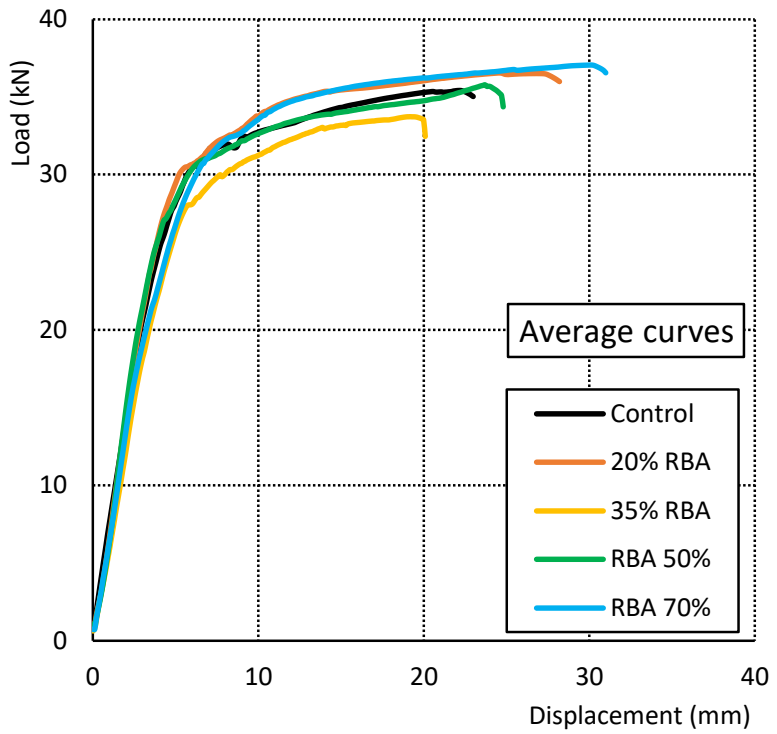

Figure 10. A flexural strength test for the set joist-rib-compression layer and average load-displacement curves.

Table 5 presents the mean value of the ultimate flexural load from-the two tests carried out for each percentage of RBA, together with the control concrete. Results of the cracking load, ductility, stiffness and flexibility for the flexural strength tests and stiffness are also shown.

\begin{tabular}{lccccccc}
\hline \multirow{2}{*}{$\%$ RBA } & \multicolumn{3}{c}{ Flexural strength test } & \multicolumn{2}{c}{ Shear strength test } \\
\cline { 2 - 9 } & $\begin{array}{c}\text { Ultimate flexural } \\
\text { load }(\mathrm{kN})\end{array}$ & $\begin{array}{c}\text { Cracking } \\
\text { load }(\mathrm{kN})\end{array}$ & Ductility & $\begin{array}{c}\text { Stiffness } \\
(\mathrm{kN} / \mathrm{mm})\end{array}$ & $\begin{array}{c}\text { Flexibility } \\
(\mathrm{mm} / \mathrm{kN})\end{array}$ & $\begin{array}{c}\text { Failure shear } \\
\text { load }(\mathrm{kN})\end{array}$ & $\begin{array}{c}\text { Cracking } \\
\text { load (kN) }\end{array}$ \\
\hline Control & 6.40 & 3.76 & 4.82 & 0.33 & 2.95 & 17.01 & 12.5 \\
\hline $20 \%$ RBA & 7.41 & 4.06 & 4.82 & 0.35 & 2.84 & 19.63 & 12.5 \\
\hline $35 \%$ RBA & 7.73 & 3.54 & 6.93 & 0.29 & 3.38 & 16.93 & 11.27 \\
\hline $50 \%$ RBA & 7.04 & 2.95 & 7.83 & 0.24 & 4.08 & 14.44 & 9.43 \\
\hline $70 \%$ RBA & 6.52 & 2.97 & 5.88 & 0.25 & 3.99 & 13.88 & 9.56 \\
\hline
\end{tabular}

Table 5. Values obtained in the flexural strength and the shear strength tests for different percentages of RBA.

The most important output of these results is that the ultimate flexural load does not decrease for any percentage studied of RBA. Rather, it always presents equal or slightly higher values than the joists manufactured with the control concrete. In fact, for intermediate values of substitution percentages (from $20 \%$ to $50 \%$ RBA) there was a slight increase in flexural strength, reaching up to an increase of

Figure 5 shows that the shape of the load-displacement curves of the joists manufactured with control concrete and that with a substitution of $20 \%$ present an initial linear plot (elastic behaviour), followed by a short curved transition zone leading to another fairly linear plot before failure. However, for substitutions above $35 \%$ the first linear part of the curve is progressively shortened as the curved transition zone increases. This increasing non-linearity is mainly due to the cracks that appear in the interface between the recycled aggregate and the cement paste, and is greater as the percentage of RBA increases. Therefore, although the ultimate flexural loads corresponding to high percentages of RBA are apparently acceptable, the behaviour of the joists is different, as they start to crack with lower loads. Figure 5 also indicates that the load corresponding to the serviceability bending moment $M_{0}$, which corresponds to the decompression bending moment of the lower fiber of the cross-section, is approximately half of the load obtained for the elastic zone of the curve for percentages of $0 \%, 20 \%$ and $35 \%$. Nevertheless, this load for $M_{0}$ is closer to the curved zone of plastic behaviour for percentages of 50 and $70 \%$. This indicates that these two last percentages of RBA provide strength values that are away from that for the joist manufactured with the control concrete. However, it is 
important to mention that all the percentages of RBA studied have an acceptable safety margin for the load corresponding to the ultimate positive bending moment $\left(\mathrm{M}_{\mathrm{u}}+\right)$.

The slope of each curve in the first linear part is related with the joist stiffness. The inverse value provides a value of the flexibility and, consequently, of the joist deflections under load. These values are included in table 5 for all substitution percentages. Ductility has also been determined as the ratio between the deflection produced by the ultimate flexural load and the deflection for the cracking bending moment. Flexural ductility provides an indication of the inelastic joist bending capability when it has to withstand a load close to its failure. It is, therefore, an important parameter from a structural point of view, because it is related to the strength capacity of the joist in the event of an overload when an accidental load, such as those than an impact, a blast or an earthquake might produce [41]. In these situations, it also provides a warning of imminent failure since considerable deflection would occur without significant loss of its load capacity. The bar diagram for these values presented in figure 10 , clearly shows the differences in the behavior of the joists for different percentages of RBA. According to this figure, ductility does not vary for a substitution level of $20 \%$ but notably increases for other percentages up to $62 \%$ in case of $50 \%$ of RBA and then ductility decreases for larger percentages of substitution.

Figure 11 presents in a bar diagrams some results of table 5 . The second bar diagram in figure 11 shows a slight rise of $8 \%$ in the cracking load for substitution level of $20 \%$ of RBA. There is a progressive decrease for percentages up to $50 \%$ and then the cracking load stabilizes for a percentage of $70 \%$.
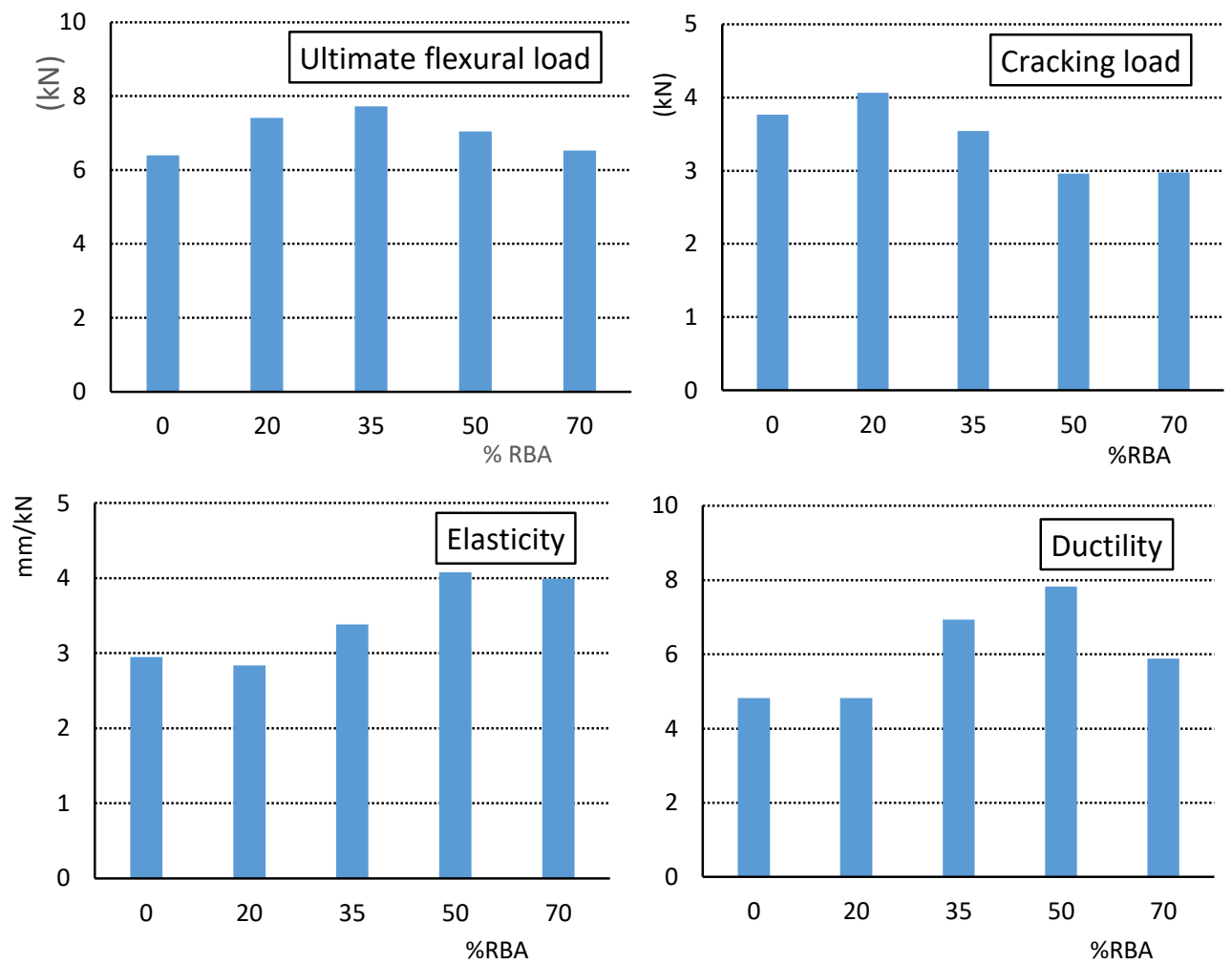

Figure 11. Ultimate flexural load, cracking load, elasticity and ductility for different percentages of RBA.

The results shown in Figure 11, obtained for the ultimate flexural load, indicate that $20 \%$ substitution is an ideal percentage, because at this proportion all the studied characteristics improved (ultimate flexural load, cracking load, elasticity and ductility). A substitution level of $35 \%$ would be an acceptable percentage with good flexural strength ( $+21 \%)$-and an improvement in ductility of $44 \%$, however, it would be necessary to accept a slight decrease in the cracking bending moment (-6\%) and an increase in the joist deflections $(+15 \%)$.

For substitutions of RBA equal to or greater than $50 \%$, although the ultimate flexural load remains at values above the control concrete, the cracking moment decreases by $21 \%$ and the deflections 
increase up to $38 \%$ from the values corresponding to the joists manufactured with the control concrete.

The results obtained by Mohammed et al. [28] in flexural strength tests of reinforced beams (not prestressed) replacing the entire coarse fraction of natural aggregates with RBA from different origins (first and second class bricks) provided an irrelevant loss in terms of ultimate flexural load and cracking moment. However, the optimal results that they obtained are explained mainly because the fine fraction of natural aggregates was not replaced.

\subsection{Shear strength test of the joists}

The results of this study indicate that the load corresponding to the ultimate shear strength $\left(V_{u}\right)$ presents an acceptable safety margin for substitution percentages of $20 \%$ and $35 \%$, but this is not the case for percentages of $50 \%$ and $70 \%$. Furthermore, the lower slope of the load-deflection curves for the latter two percentages implies large deflections. Consequently, the results are lower to those obtained for joists manufactured with the control concrete.

Table 5 presents the mean value of the ultimate loads obtained from the two shear strength tests carried out for each percentage of substitution with RBA. As in the flexural strength tests, the point at which the elastic behaviour finishes, which corresponds to the load at which the first crack appears, was also obtained. The results are presented in a bar diagram in figure 12.

It can be observed that the ultimate load obtained in the shear strength tests for percentages of $20 \%$ and $35 \%$ of RBA reached better $(+15 \%)$ or equal results than those of the joists prepared with the control concrete. Nevertheless, the ultimate load decreased between $15 \%$ and $18 \%$ for percentages of substitution of $50 \%$ and $70 \%$. Regarding cracking load, the results showed that for $20 \%$ of RBA there was almost no variations in comparison to joist with the control concrete while for a substitution of $35 \%$ the results were acceptable assuming a decrease of $10 \%$.
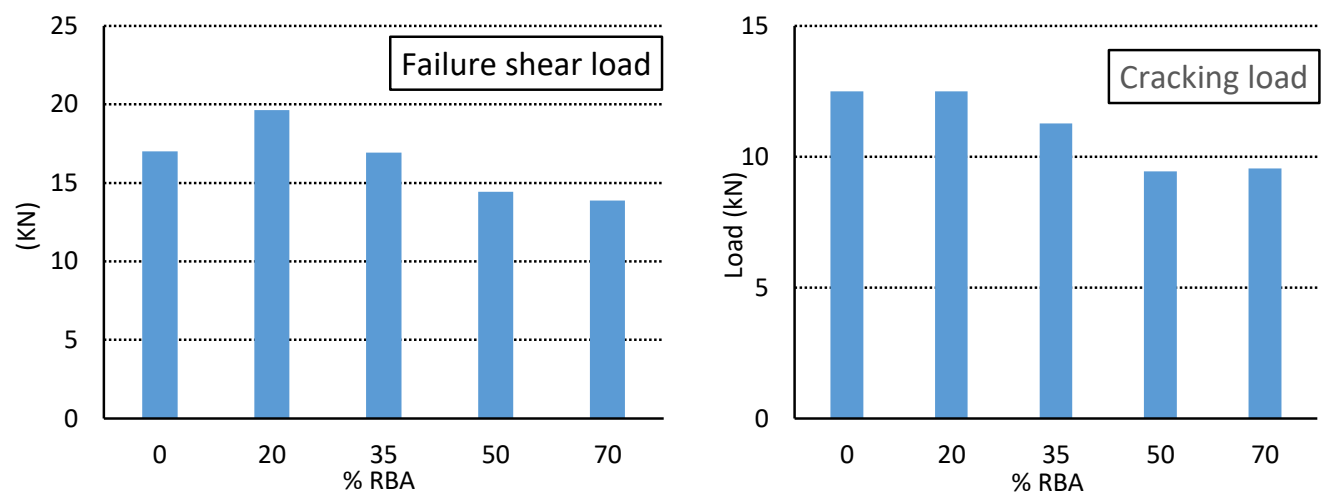

Figure 12. Failure shear load and cracking load in the shear strength test.

Regarding the shear strength tests, it can be concluded that for 20\% of RBA, the results are more than acceptable since all the parameters improve, although with a very slight increase in deflections. For a substitution of $35 \%$, the results are very similar to those of the joists manufactured with the control concrete. So it would be a percentage of substitution, perfectly usable. However, for values of $50 \%$ and $70 \%$, the results are less favourable since the loss of strength in terms of the appearance of the first micro-cracks decreases by $25 \%$ and deflections increase up to $29 \%$.

\subsection{Flexural strength test for the set joist-rib}

When studying the mechanical response of the joists-rib-compression layer set, it is clear that the results will depend not only on the mechanical properties of the joists but also on the specimens tested with different percentages of RBA are presented in table 6 and its graphic representation is shown in 


\begin{tabular}{lc}
\hline \%RBA & Ultimate flexural load $(\mathrm{kN})$ \\
\hline Control & 35.45 \\
20\% RBA & 36.59 \\
35\% RBA & 33.79 \\
50\% RBA & 35.42 \\
70\% RBA & 36.92 \\
\hline
\end{tabular}

Table 6. Flexural strength test for the joist-rib-compression layer set.

Figure 13 shows that the results of flexural strength of for different percentages of RBA are very similar. Only a slight decrease in strength is observed in the case of floor slabs manufactured with joists that include $35 \%$ and 50\% RBA. This reduction can be explained because in these cases the concrete used for the compression layer was slightly more fluid, which generated a slight loss of strength.

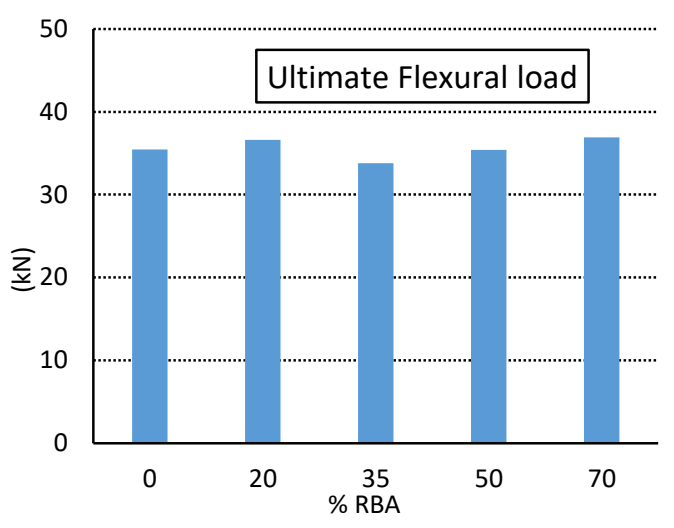

Figure 13. Ultimate flexural load for the joist-rib-compression layer set.

The load-displacement curves shown in figure 10 are all very similar, with differences below $10 \%$. Therefore, prestressed joists manufactured with recycled aggregates can be used with high percentages of substitution (up to 70\%) in floor-slabs in which the rib and the compression layer are elaborated with conventional concrete provided they have an adequate compressive strength.

\subsection{Combined analysis of results}

If the analysis is focused on the isolated joists, for a substitution of 20\% RBA an improvement of the mechanical response and a reduction of deflections were observed. However, in table 3 with regards the properties of concrete, according to the preliminary study [36], a slow decrease in the properties of concrete, when the percentage of RBA increases, are presented. In order to explain this difference, it is necessary to take into account that, in the manufacturing process of the joists, the total amount of water was reduced, regarding the quantity used in the laboratory, for all the percentages of RBA. Due to this fact, the effective ratio water/cement decreases when the percentage of RBA increases due to the high absorption of RBA, which explain the improvement of the joists behaviour. In previous studies [31,33,34] it has been mentioned, although the coarse fraction of RBA tends to produce an unfavourable effect, also commented in previous studies [31, 42]. Also, the effect on the curing process that these types of aggregates can produce should be added. This effect is well known in the field of high-strength concrete (HPC) in which there is a higher risk of reducing the internal humidity of the concrete that is necessary to keep the hydration of cement, as well as the pozzolanic reactions. One of the solutions provided in the literature to overcome this problem in the field of HPC is the use of porous ceramic aggregates, not only in the fine fraction [43], but also in the coarse fraction, with percentages of up to $40 \%$ [44]. However, an excessive increase in the coarse fraction of RBA produces a different effect since, due to its lower mechanical strength, it tends to fracture more easily than when natural aggregates are used [42].

When the percentage of substitution with RBA reaches $35 \%$ the results in terms of the mechanical response of the joists were similar or slightly worse than those for joists manufactured with the control 
concrete. The ultimate flexural load improved by $21 \%$, the shear strength remained the same, the cracking load for the first crack appearance decreased between $6 \%$ and $10 \%$ (depending on the type of test), deflections are increased a $15 \%$ and ductility improved a $44 \%$. This percentage of substitution $(35 \%)$ is a kind of threshold point, at which the favourable effects of fine RBA are balanced with the unfavourable effects of the coarse fraction of this type of aggregate. With this percentage of replacement, most of the mechanical properties of the control concrete joists are maintained. Although a slight increase in deflections under bending must be accepted (15\%), this is an admissible limit for both fine and coarse RBA aggregates for the manufacture of prestressed joists. These results are similar to those obtained by Cheng et al. [30].

For a level of substitution of $50 \%$ the ultimate flexural strength remains still $10 \%$ better than the joists prepared with the control concrete, but the shear strength decreases by $15 \%$. The cracking load also decreases in a range between $21 \%$ and $25 \%$, depending on the type of test, and deflections increase by $38 \%$. In general, these are certainly relevant values which represent a significant drop when they are compared to those obtained with $35 \%$ substitution. Therefore, this percentage of substitution with RBA would not be recommended unless the aforementioned losses of strength were accepted, together with the associated increase in deflections. For the percentage of $70 \%$ the results obtained were similar. The increase in the deflections for these two percentages of RBA are directly related to the drop in the stiffness of the concrete used in the manufacture of the joists (table 3 ). The elastic modulus was reduced by $30 \%$ for $50 \%$ RBA and up to $45 \%$ for $70 \%$ RBA.

It is not easy to establish a comparison with the results obtained by other authors since in those cases only the coarse fraction of RCA was used, due to the unfavourable effect of the fine fraction of this aggregate. In this study both the coarse and the fine fractions of aggregate (RBA) were used. Furthermore, in this work prestressed joists have been tested, while the works found in the literature refer to conventional reinforced concrete beams. In any case, it can be established that for replacement percentages up to $35 \%$ the effect of the RBA on the flexural and shear strength of the joists is more advantageous than replacing only the coarse fraction of RCA. Nevertheless, for percentages higher than $35 \%$ the substitution with only the coarse fraction of RCA is more favourable.

Regarding the results obtained when studying the mechanical behaviour of the complete floor slab, (the set comprised by the joist, the rib and the compression layer), when using conventional concrete in the preparation of this layer, the differences compared with the results from the isolated joists are negligible. A consequence is that replacement rates with RBA up to $70 \%$ can be used in floor slabs if conventional concrete is used for the compression layer, without significant loss of mechanical strength or increase in deflections.

Other important issue that must be evaluated in the joists manufactured with RBA used in structural applications is the flexibility. In the final phase of this research, corresponding to the measures of the shrinkage and the creep in the concrete used in this study, it will be explained. These tests, results and conclusions will be the main issue of another work in a near future.

\section{Conclusions}

- The results derived from the flexural strength tests carried out on joists manufactured with RBA show a clear improvement in their behaviour for a replacement of $20 \%$. When the replacement percentage reaches $35 \%$ the results are similar to those obtained for joists prepared with control concrete, although with a slight increase in the deflections. However, for percentages of $50 \%$ and $70 \%$ the flexural strength is clearly lower since the cracking bending moment decreases up to $21 \%$ and the joist deflections increases up to $28 \%$.

- The results obtained from the shear strength tests on the joists with RBA show that for a $20 \%$ substitution there is almost no variations in comparison to the joist manufactured with the control concrete. At $35 \%$ of RBA the results are acceptable although there is a slight decrease in the cracking load. However, for replacements of $50 \%$ and $70 \%$ the results are less favourable 
due to the loss of strength and also the cracking load decreases by $25 \%$ and deflections increase by $20 \%$.

- The general assessment of this study regarding the isolated joist is that a percentage of substitution with RBA of $20 \%$ does not produce negative effects. In fact, it is desirable because all the mechanical properties improve. - In the case of a substitution percentage of $35 \%$ very slight differences are observed in the strength of the joists. So it would be the most recommendable substitution percentage. However, for $50 \%$ or higher substitution levels, the loss of strength, as well as the increase in deflections are significant and therefore, it would not be recommended.

- When conventional concrete is used in the preparation of the rib and the compression layer during the construction of a floor slab, the losses of mechanical strength of the joists prepared with high percentages of RBA become negligible. Thus, up to $70 \%$ of RBA could be used without a significant variation in the results of the mechanical strength of the floor slab.

\section{Acknowledgments}

This paper is part of the research projects BIA2012-30915 and BIA2016-78460-C3-2-R sponsored by the Spanish Ministry of Economy and Competitiveness to which the authors express their gratitude. We would also like to thank the cooperation of Rubiera Predisa S.L., La Belonga Impulso Alternativo, Horavisa, Lafarge-Holcim Spain, BASF España, Silmin Ibérica S.A. and Secil Spain for their support.

\section{References}

[1] European-Commission, $\operatorname{COM(2011)~} 571$ Roadmap to a Resource Efficient Europe. Communication from the Commission to the European Parliament., 2011.

[2] M.D. Merino, P.I. Gracia, I.S.W. Azevedo, Sustainable construction: construction and demolition waste reconsidered, Waste Management \& Research 28(2) (2010) 118-129.

[3] F. Pacheco-Torgal, S. Jalali, Reusing ceramic wastes in concrete, Construction and Building Materials 24(5) (2010) 832-838.

[4] R. Sato, I. Maruyama, T. Sogabe, M. Sog, Flexural behavior of reinforced recycled concrete beams, Journal of Advanced Concrete Technology 5(1) (2007) 43-61.

[5] W.C. Choi, H.D. Yun, S.W. Kim, Flexural performance of reinforced recycled aggregate concrete beams, Magazine of Concrete Research 64(9) (2012) 837-848.

[6] M. Arezoumandi, A. Smith, J.S. Volz, K.H. Khayat, An experimental study on flexural strength of reinforced concrete beams with 100\% recycled concrete aggregate, Engineering Structures 88 (2015) 154-162.

[7] W. Bai, B. Sun, Experimental Study on Flexural Behavior of Recycled Coarse Aggregate Concrete Beam, Applied Mechanics and Mechanical Engineering, Pts 1-3 29-32 (2010) 543-548.

[8] I.S. Ignjatovic, S.B. Marinkovic, Z.M. Miskovic, A.R. Savic, Flexural behavior of reinforced recycled aggregate concrete beams under short-term loading, Materials and Structures 46(6) (2013) 10451059.

[9] S.C. Deng, F. Yu, EXPERIMENTAL STUDIES OF FLEXURAL STRENGTH AND MECHANICS PERFORMANCE FOR RECYCLED CONCRETE BEAM, 2nd International Conference on Waste Engineering and Management, Tongji Univ, Shanghai, PEOPLES R CHINA, 2010, pp. 695-+.

[10] S.L. Zhao, C. Sun, Experimental Study of the Recycled Aggregate Concrete Beam Flexural Performance, Frontiers of Green Building, Materials and Civil Engineering lii, Pts 1-3 368-370 (2013) 1074-+.

[11] A.M. Knaack, Y.C. Kurama, Behavior of Reinforced Concrete Beams with Recycled Concrete Coarse Aggregates, Journal of Structural Engineering 141(3) (2015).

[12] A.M. Knaack, Y.C. Kurama, Sustained Service Load Behavior of Concrete Beams with Recycled Concrete Aggregates, Aci Structural Journal 112(5) (2015) 565-577.

[13] N. Tosic, S. Marinkovic, I. Ignjatovic, A database on flexural and shear strength of reinforced recycled aggregate concrete beams and comparison to Eurocode 2 predictions, Construction and Building Materials 127 (2016) 932-944. 
[14] EN 1992-1-1, Eurocode 2: Design of concrete structures - Part 1-1: General rules and rules for buildings., CEN, Brussels, 2004.

[15] R.V. Silva, J. de Brito, L. Evangelista, R.K. Dhir, Design of reinforced recycled aggregate concrete elements in conformity with Eurocode 2, Construction and Building Materials 105 (2016) 144-156.

[16] M. Arezoumandi, A. Smith, J.S. Volz, K.H. Khayat, An experimental study on shear strength of reinforced concrete beams with $100 \%$ recycled concrete aggregate, Construction and Building Materials 53 (2014) 612-620.

[17] H. Katkhuda, N. Shatarat, Shear behavior of reinforced concrete beams using treated recycled concrete aggregate, Construction and Building Materials 125 (2016) 63-71.

[18] K.N. Rahal, Y.T. Alrefaei, Shear strength of longitudinally reinforced recycled aggregate concrete beams, Engineering Structures 145 (2017) 273-282.

[19] Z.P. Chen, Y.L. Chen, W.D. Ying, M. Zhong, EXPERIMENTAL STUDY ON THE SHEAR MECHANICAL BEHAVIOR OF STEEL REINFORCED RECYCLED COARSE AGGREGATE CONCRETE BEAMS, Proceedings of the Twelfth International Symposium on Structural Engineering, Vols I and Ii (2012) 1413-1417.

[20] E.E. Ikponmwosa, M.A. Salau, Tms, SHEAR CAPACITY OF REINFORCED CONCRETE BEAMS USING RECYCLED COARSE AGGREGATES, Tms2011 Supplemental Proceedings, Vol 3: General Paper Selections (2011) 419-426.

[21] W.C. Choi, H.D. YUn, SHEAR STRENGTH OF REINFORCED RECYCLED AGGREGATE CONCRETE BEAMS WITHOUT SHEAR REINFORCEMENTS, Journal of Civil Engineering and Management 23(1) (2017) 76-84.

[22] I.S. Ignjatovic, S.B. Marinkovic, N. Tosic, Shear behaviour of recycled aggregate concrete beams with and without shear reinforcement, Engineering Structures 141 (2017) 386-401.

[23] B. Gonzalez-Fonteboa, F. Martinez-Abella, Shear strength of recycled concrete beams, Construction and Building Materials 21(4) (2007) 887-893.

[24] G. Fathifazl, A.G. Razaqpur, O.B. Isgor, A. Abbas, B. Fournier, S. Foo, Shear capacity evaluation of steel reinforced recycled concrete (RRC) beams, Engineering Structures 33(3) (2011) 1025-1033.

[25] G. Fathifazl, A.G. Razaquur, O.B. Isgor, A. Abbas, B. Fournier, S. Foo, Shear strength of reinforced recycled concrete beams without stirrups, Magazine of Concrete Research 61(7) (2009) 477-490.

[26] A.G. Razaqpur, G. Fathifazl, B. Isgor, A. Abbas, B. Fournier, S. Foo, HOW TO PRODUCE HIGH QUALITY CONCRETE MIXES WITH RECYCLED CONCRETE AGGREGATE, 2nd International Conference on Waste Engineering and Management, Tongji Univ, Shanghai, PEOPLES R CHINA, 2010, pp. 11-+.

[27] G. Fathifazl, A.G. Razaqpur, O.B. Isgor, A. Abbas, B. Fournier, S. Foo, Flexural Performance of SteelReinforced Recycled Concrete Beams, Aci Structural Journal 106(6) (2009) 858-867.

[28] T.U. Mohammed, H.K. Das, A.H. Mahmood, M.N. Rahman, M.A. Awal, Flexural performance of RC beams made with recycled brick aggregate, Construction and Building Materials 134 (2017) 6774.

[29] A.C. Institute, ACI 318-14 (Building Code Requirements for Structural Concrete and Commentary), Farmington Hills, Michigan, 2014.

[30] Y.B. Cheng, G.H. Qiao, Experimental Study of the Flexural Behavior of Concrete Beams with Recycled Brick Aggregate, Proceedings of the 2015 4th International Conference on Sustainable Energy and Environmental Engineering 53 (2016) 79-82.

[31] F. Debieb, S. Kenai, The use of coarse and fine crushed bricks as aggregate in concrete, Construction and Building Materials 22(5) (2008) 886-893.

[32] P.B. Cachim, Mechanical properties of brick aggregate concrete, Construction and Building Materials 23(3) (2009) 1292-1297.

[33] A.V. Alves, T.F. Vieira, J. de Brito, J.R. Correia, Mechanical properties of structural concrete with fine recycled ceramic aggregates, Construction and Building Materials 64 (2014) 103-113.

[34] J.M. Khatib, Properties of concrete incorporating fine recycled aggregate, Cement and Concrete Research 35(4) (2005) 763-769. 
[35] A.E.B. Cabral, V. Schalch, D.C.C. Dal Molin, J.L.D. Ribeiro, Mechanical properties modeling of recycled aggregate concrete, Construction and Building Materials 24(4) (2010) 421-430.

[36] J.S. Gonzalez, F.L. Gayarre, C.L.C. Perez, P.S. Ros, M.A.S. Lopez, Influence of recycled brick aggregates on properties of structural concrete for manufacturing precast prestressed beams, Construction and Building Materials 149 (2017) 507-514.

[37] EN 206-1 Concrete. Part 1: Specification, performance, production and conformity, Brussels, 2008.

[38] EN-10027:2006 Designation systems for steels - Part 1: Steel names, Brussels, 2006.

[39] EN 15037-1 Precast concrete products. Beam-and-block floor systems. Part 1: Beams, Brussels, 2010.

[40] EHE 08 Code on structural concrete, Ministerio de Fomento de España, Spain, 2010.

[41] A.K.H. Kwan, C.M. Ho, H.J. Pam, Flexural strength and ductility of reinforced concrete beams, Proceedings of the Institution of Civil Engineers-Structures and Buildings 152(4) (2002) 361-369.

[42] J. Brito, A.S. Pereira, J.R. Correia, Mechanical behaviour of non-structural concrete made with recycled ceramic aggregates, Cement \& Concrete Composites 27(4) (2005) 429-433.

[43] D.P. Bentz, K.A. Snyder, Protected paste volume in concrete - Extension to internal curing using saturated lightweight fine aggregate, Cement and Concrete Research 29(11) (1999) 1863-1867.

[44] M. Suzuki, M.S. Meddah, R. Sato, Use of porous ceramic waste aggregates for internal curing of high-performance concrete, Cement and Concrete Research 39(5) (2009) 373-381. 